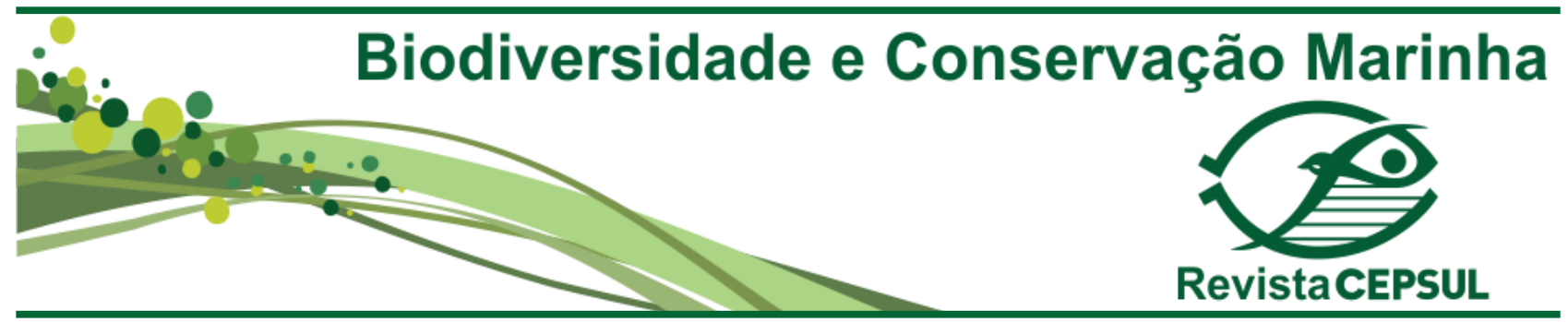

Opinião

\title{
Manejo da pesca do guaiamum: uma alternativa para conservação das áreas de apicum do nordeste oriental brasileiro
}

\author{
Maria do Carmo Ferrão Santos ${ }^{1}$ \& Fabiano Pimentel Ribeiro ${ }^{1}$
}

\begin{abstract}
${ }_{1}^{1}$ Analista Ambiental do Centro Nacional de Pesquisa e Conservação da Biodiversidade Marinha do Nordeste - ICMBio/CEPENE , $R$. Dr. Samuel Hardman, CEP - 55578-ooo, Tamandaré, PE, Brasil, maria-carmo.santos@icmbio.gov.br, fabiano.ribeiro@icmbio.gov.br.
\end{abstract}

Submetido em: 16/o2/2019; Aceito em: 3o/o4/2019; Publicado em: 14/10/2019

Resumo. O guaiamum, Cardisoma guanhumi Latreille, 1828 (Brachyura: Gecarcinidae), é um crustáceo amplamente capturado por populações tradicionais de pescadores artesanais no nordeste brasileiro. Esse crustáceo foi considerado Criticamente em Perigo (CR) e está no Livro Vermelho da Fauna Brasileira Ameaçada de Extinção. Como medida de conservação, foi publicada a Portaria Interministerial do Governo Brasileiro que define regras para o uso sustentável e para a recuperação dos estoques do guaiamum. Entretanto, o conteúdo dessa Portaria tende a gerar a institucionalização de conflitos socioambientais na medida em que inviabiliza socioeconomicamente a atividade artesanal da pesca e possibilita o uso de áreas de apicum por grandes empreendimentos. Para subsidiar as discussões sobre a gestão do uso dessa espécie, este trabalho traz informações e análises de algumas publicações sobre o tamanho de captura, assim como o tamanho de primeira maturação, e sugere regionalização nas medidas de manejo para o uso sustentável do guaiamum.

Palavras-chave: Cardisoma guanhumi, conflito socioambiental, manguezal, apicum.

\begin{abstract}
Guaiamum fishing management: an alternative for conservation of apicum areas of the Brazilian eastern northeast. Guaiamum, Cardisoma guanhumi Latreille, 1828 (Brachyura: Gecarcinidae), is a crustacean widely captured by traditional populations of artisanal fishermen in northeastern Brazil. This crustacean was considered Critically Endangered (CR) and is in the National Official List of Threatened Species. As a conservation rule, the Brazilian government published an interministerial ordinance that defines rules for sustainable use and for recovering stocks of guaiamum. However the content of these rules tends to generate socio-environmental conflicts when it makes the artisanal fishing activity unfeasible socioeconomically and allows the use of apicum areas by large enterprises. To support discussions on the management of the use of this species, this work brings information and analyzes of some publications, on the average size of the catch,
\end{abstract}


as well as the first maturation size of the crustacean, and suggests regionalization in the management rules for the sustainable use of guaiamum.

Keywords. Cardisoma guanhumi, socio-environmental conflict, fishing management, apicum.

\section{As populações tradicionais, os apicuns e os guaiamuns}

O caranguejo guaiamum (goiamum, caranguejo-azul, caranguejo-do-mato), Cardisoma guanhumi Latreille, 1828 (Brachyura: Gecarcinidae), é consumido no território brasileiro desde os seus primeiros habitantes - os índios. É conhecido por apresentar crescimento lento em relação a outros caranguejos, além de possuir grande longevidade. Até a fase adulta são estimadas cerca de 60 mudas. Na natureza a espécie pode atingir até 13 anos de idade, e largura da carapaça em torno de $10,0 \mathrm{~cm}$. Apresenta distribuição geográfica ao longo da Costa Atlântica do continente Americano, desde a Flórida (EUA) até Santa Catarina (Brasil). No Brasil é secularmente explorado, em especial na região Nordeste, por populações tradicionais de pescadores artesanais, que o consomem ou vendem, como forma de completar a sua renda familiar, portanto, possui elevada importância socioeconômica e cultural (Henning, 1975a; Melo, 1996; Wedes, 2004; Botelho et al., 2009). Povos e Comunidades Tradicionais "são grupos culturalmente diferenciados e que se reconhecem como tais, que possuem formas próprias de organização social, que ocupam e usam territórios e recursos naturais como condição para sua reprodução cultural, social, religiosa, ancestral e econômica, utilizando conhecimentos, inovações e práticas gerados e transmitidos pela tradição" (Brasil, 2007).

O excesso de captura do guaiamum ocorre por diversos fatores, como: a mortalidade em massa do caranguejo-uçá (Ucides cordatus) do Ceará a Bahia, entre 1996 e 2006, quando muitos catadores desta espécie migraram para a captura do guaiamum; devido à falência de diversas usinas de açúcar; como pelo período da entressafra daquelas em atividade, fazendo com que milhares de pessoas desempregadas atuem na captura do guaiamum (Botelho et al., 2009). Além disso, é um crustáceo de fácil captura por construir suas tocas próximas às áreas habitadas e de fácil acesso. Soma-se a isso, o elevado valor comercial que a espécie possui, por ser um dos pratos mais tradicionais da culinária nordestina.

Esse caranguejo de valor econômico, com elevado grau de terrestrialidade, depende de um substrato que possibilite escavar suas galerias usadas como abrigo. Nas últimas décadas, tem sofrido declínio populacional causado, principalmente, pela degradação de seu habitat por grandes empreendimentos, como construções de fazendas de camarão que têm ocupado grandes áreas desde a década de 1980, aproveitando o solo da planície hipersalina, também conhecida como apicum, na construção dos diques (Schmidt, 2013). Através dos trabalhos de campo, os autores perceberam que no nordeste oriental, o uso imobiliário, o desmatamento, a extração da madeira, a construção de vias de acesso, as plantações, a criação de animais, a poluição, as queimadas, entre outros fatores, também ocasionam a degradação de grandes extensões do habitat do guaiamum.

De acordo com seu crescimento, o guaiamum vai migrando para a terra firme. $\mathrm{O}$ apicum, localizado na transição da zona úmida para a terra firme, constitui habitat para o guaiamum e para diversas espécies de vegetação herbácea. Esse ambiente é pouco inundado pelas águas intersticiais nas preamares, e mesmo com muita discussão sobre a definição dos limites do apicum, sua importância como uma feição ecológica do ecossistema manguezal é reconhecida pelos pesquisadores (Coelho-Jr, 2010). 
Segundo Schmidt (2013), em relação aos efeitos de mudanças climáticas, "talvez a maior importância do apicum esteja no fato de poder impedir a redução da área ocupada pelos manguezais, com o aumento do nível médio relativo do mar". Soma-se a isso, que o apicum faz parte da vida dos pescadores artesanais que o utilizam não só para exercer sua atividade econômica, mas também como lugar de lazer. Como diz Seu Chico, pescador de Rio Formoso, Pernambuco, “... esse lugar é um lazer para nós, sempre final de tarde, quando a maré está boa, as mulheres com a as crianças vêm tomar banho na salina...”. Os pescadores chamam o apicum de "salina". Talvez porque ao se caminhar sobre o apicum veem-se cristais de sal no chão de areia brilhando sob o sol. Ainda de acordo com Seu Chico, "é como se ver estrelas no chão...". O termo "salina" também é usado para os empreendimentos de extração de sal que ficam no apicum.

A importância socioeconômica do guaiamum, e do apicum, torna esse ambiente biofísico um campo de conflitos socioambientais. Se por um lado, os pescadores dependem desse ambiente, por outro, grandes empreendedores visam o apicum como espaços de implantação de seus negócios.

Tal fato vem se tornando cada vez mais relevante, devido à perda do habitat pela especulação imobiliária, atividades agropastoris e carcinicultura (Botelho et al., 2009). É provável que esses empreendimentos tenham influência na mudança da estrutura da população do guaiamum, com redução do número de indivíduos adultos no ambiente. Essa redução tem levado à exploração de indivíduos mais jovens, que reflete no valor comercial do caranguejo.

Apesar do apicum ser uma zona de transição importante para a biodiversidade, ainda existem poucos estudos que contribuem para uma definição apropriada e para determinar os padrões de distribuição dessa biodiversidade ao longo dessa zona. Tal fato tem fortalecido a defesa de que o apicum não consiste numa zona do manguezal e que, portanto, poderia estar sujeito à exploração para atividades como carcinicultura e exploração de sal marinho.

\section{As políticas públicas e a injustiça ambi- ental}

No Brasil existe uma escassez de informações precisas sobre a biologia, pesca e situação dos habitats do guaiamum. Entre os anos de 2009 e 2010, ocorreram discussões sobre esta população, por ter sido considerada ameaçada. No âmbito dessas discussões, foram levadas as seguintes alegações: o aumento de seu preço de comercialização e, a estimativa de diminuição no tamanho médio dos indivíduos no ambiente (ICMBIO, 2018). Também foi levantada a questão da redução do habitat, cuja área vem sendo ocupada pela expansão urbana e supressão da vegetação natural, principalmente a restinga (Pinheiro, et al., 2016), pois, traz para a discussão o problema de envolver outros agentes sociais para o uso sustentável do guaiamum.

Soma-se a isso, que essa carência de estudos tem possibilitado questionamentos de agentes sociais do setor da carcinicultura, do turismo, de empreendimentos imobiliários e de produção de sal marinho, sem comprovação científica, que o apicum não consiste numa zona de manguezal, podendo estar sujeito à exploração de grandes empreendimentos (Schmidt, 2013). O fato que mais evidenciou o nível de pressão dos grandes empreendimentos sobre os apicuns foi à aprovação da Lei $\mathrm{N}^{\mathrm{O}}$ 12.651, de 25 de maio de 2012, também conhecida como "Novo Código Florestal", na qual os apicuns passaram a ser definidos à parte do ecossistema manguezal. A aprovação dessa lei foi emblemática, pois, levou-se a uma discussão a nível nacional, na qual o embate se deu entre os ambientalistas, que criticavam o conteúdo da lei, e os ruralistas, que a defendiam, com a vitória dos últimos.

A aprovação da referida lei, na prática, possibilita o uso do apicum por carcinicultura e salinas, como está descrito no Parágrafo $1^{\circ}$ do Artigo, $\mathrm{n}^{0}$ 11: "Os apicuns e salgados podem ser utilizados em atividades de carcinicultura e salinas, desde que observados os seguintes 
requisitos...”. Pelo Novo Código Florestal, o apicum deixou de ser uma Área de Preservação Permanente (APP) e tornou-se um ambiente passível de ser alterado por grandes empreendimentos. Portanto, a aprovação dessa lei representou um retrocesso para conservação da biodiversidade.

Por outro lado, o Ministério do Meio Ambiente (MMA), visando à conservação da biodiversidade, publicou a Portaria $\mathrm{n}^{\mathrm{o}} .445$, em 17 de dezembro de 2014 (Brasil, 2014), que contém a lista nacional de espécies ameaçadas, as quais, dependendo da categoria, estariam proibidas de serem capturadas. Nesta portaria, o guaiamum foi categorizado como espécie Criticamente em Perigo (CR). Apenas após a publicação da Portaria MMA n ${ }^{0} 128$, de 27 de abril de 2018 (Brasil, 2018a), a espécie foi reconhecida como passível de ser explorada. Contudo, tal portaria estabelece que o uso do guaiamum esteja condicionado à elaboração de um Plano de Recuperação da Espécie. Portanto, a captura do guaiamum ficou proibida por cerca de quatro anos, mesmo não sendo esta atividade, a principal ameaça à espécie.

Após publicação da Portaria 445, iniciou-se amplo embate dos movimentos sociais de pescadores artesanais com os órgãos responsáveis pela gestão ambiental, no qual os primeiros reivindicavam direitos de uso da espécie, frente à abertura da degradação do apicum, pelo 'Novo Código Florestal'.

O Plano de Recuperação do Guaiamum (Brasil, 2018ab) estabelece algumas medidas, como tamanho mínimo de captura, restrições de tipos de apetrechos e períodos de captura. Essas medidas são universais no manejo do uso de recursos pesqueiros, em território nacional, e apontam uma nova estratégia de conservação da espécie, pois, o manejo do uso do guaiamum possibilita a permanência de populações tradicionais de catadores em seus territórios e, consequentemente, a conservação do ambiente de apicum frente aos grandes empreendimentos.

Entretanto, apesar de observar-se os avanços nas conquistas para que as populações de pescadores artesanais continuem a capturar o guaiamum, algumas medidas adotadas no
Plano Nacional de Recuperação dessa espécie, não contemplam a realidade da atividade ao longo da costa brasileira, pois, os tamanhos dos animais de populações de guaiamum do nordeste oriental brasileiro não condizem com o tamanho mínimo de captura determinado pelo referido plano. Ou seja, o Plano Nacional de Recuperação do Guaiamum (Brasil, 2018b) inviabilizará futuras propostas de manejos locais do guaiamum, principalmente provenientes do nordeste oriental brasileiro.

As políticas públicas ambientais, no caso da conservação dos guaiamuns, têm sido ambíguas, pois, a lei tem beneficiado grandes interesses do capital que alteram o habitat do guaiamum, e é o principal foco de ameaça à espécie, e ao mesmo tempo, impõe regras que inviabilizam socioeconomicamente a atividade de populações tradicionais. Essa injustiça ambiental levará os catadores de guaiamum do nordeste oriental brasileiro, inicialmente, à ilegalidade, e, posteriormente, à paralização das atividades pesqueiras, em paralelo ao aumento de implantação de grandes empreendimentos no habitat da espécie ameaçada.

\section{As populações de guaiamum no nordeste oriental brasileiro}

De acordo com a Proposta de Plano Nacional de Gestão para o Uso Sustentável do Caranguejo-Uçá, do Guaiamum e do Siri-Azul, no que se refere ao guaiamum, de 1994 a 1995 ocorreu grande queda na produção total, passando de $685 \mathrm{t}$ para $126 \mathrm{t}$ (IBAMA, 2011). Considerando o período de 1994 a 2007, ao excluirmos o primeiro ano da série, observa-se que a tendência de queda da produção se manteve de 1995 (126 t) a 1998 (10,5 t), seguida de uma quase que estabilidade em 1999 e em 2000. Entre 2001 e 2003 ocorreram recuperações, retornando ao patamar próximo de $100 \mathrm{t}$. Em 2004 , foi observada redução para $55,5 \mathrm{t}$, seguida de um novo período de suave recuperação, quando a produção de 2007 atingiu 89,5 toneladas (Figura 1).

No Brasil, antes de 1994 praticamente não existem informações sobre a produção pes- 


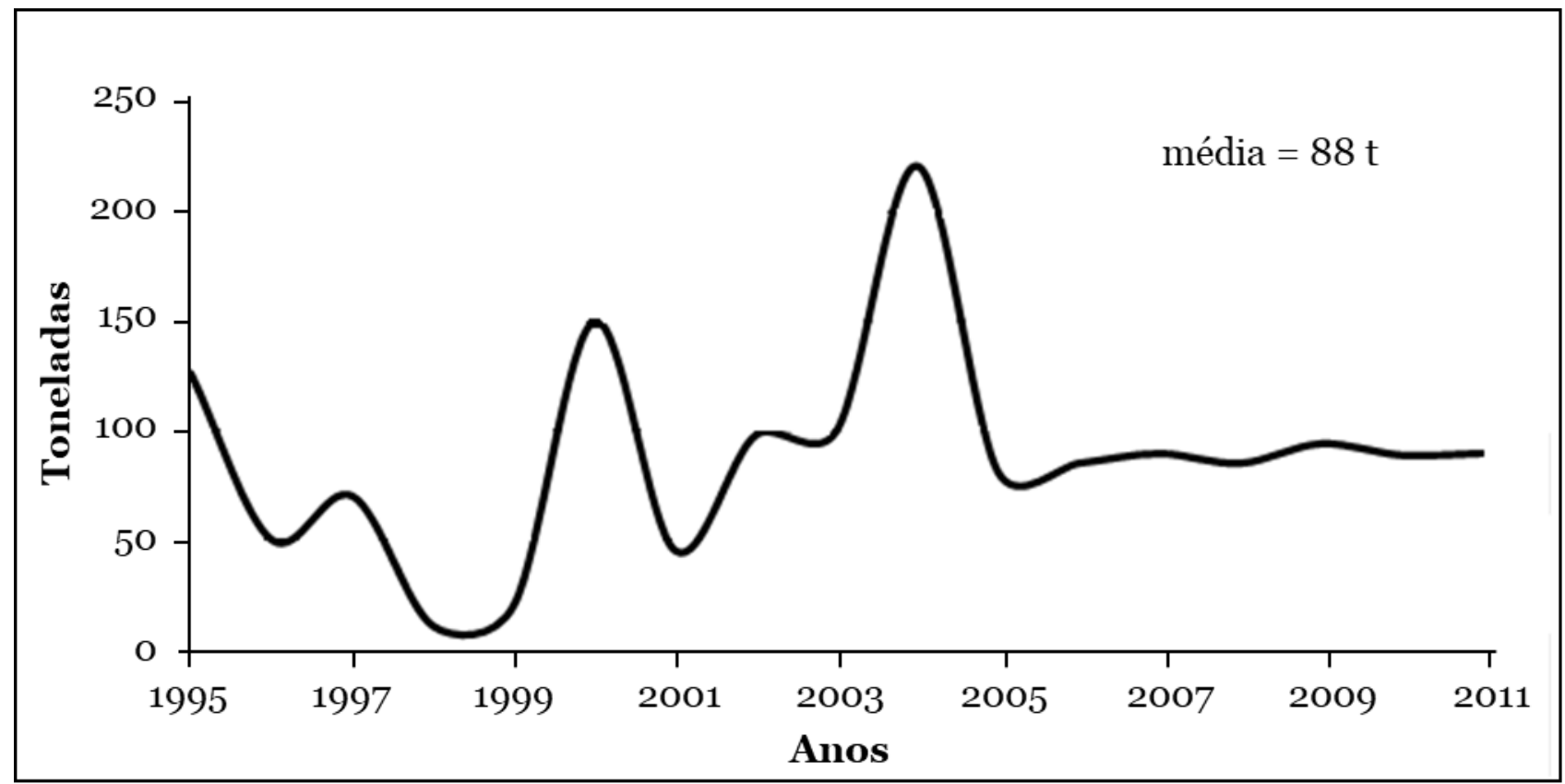

Figura 1. Produção brasileira anual do Cardisoma guanhumi, de 1995 a 2011. Fonte: IBAMA, 2000-20012002-2003-2004-2005a, e 2011; MPA, 2012

queira do guaiamum. A partir daí, só há dados de estatística pesqueira com informações de produção e esforço de pesca para o estado de Sergipe, embora a espécie se destaque na culinária em todo o litoral nordestino. O que motivou tal fato foi à metodologia aplicada no programa ESTATPESCA (IBAMA-MMA), na qual cada estado pôde optar pelas espécies que deveriam ser monitoradas ao longo do tempo, portanto, apenas Sergipe monitorou o guaiamum.

A estimativa da produção de guaiamum em Sergipe, no período de 1995 a 2011, variou de 11,0 toneladas (em 1998) a 221,1 toneladas (em 2004), com média no período de 88,o toneladas/ano. Portanto, tudo faz crer que existem algumas discrepâncias, especialmente no ano de 2004, quando a produção nacional foi de 55,5 t (IBAMA, 2011), porém, apenas Sergipe totalizou 221,1 $\mathrm{t}$ (IBAMA, 2005) (Figura 1).

Nos últimos 15 anos, a obtenção de informações pesqueiras, que nas décadas anteriores funcionava sob a responsabilidade de coletores com vínculo efetivo com a SUDEPE e depois transferidos para o IBAMA, foi substituída por uma rede de coleta atrelada a diferentes parcerias. No geral, pouco se sabe sobre a produção comercial de guaiamum; já a produção de subsistência para fins alimentares, embora de extremo valor social para os nordestinos, esta praticamente não possui qualquer registro.

Independente de sexo, em algumas localidades foi registrada a largura da carapaça (LC) dos guaiamuns capturados comercialmente. Em São José da Coroa Grande (litoral sul de Pernambuco), variou entre $3,1 \mathrm{~cm} \mathrm{e} 7,4 \mathrm{~cm}$, com média de $5,2 \mathrm{~cm}$; do total de 1.440 indivíduos amostrados, apenas $0,3 \%$ teve $7,0 \mathrm{~cm}$ ou mais de largura da carapaça (Botelho et al., 2001). Em Caravelas (litoral sul da Bahia), variou entre $3,0 \mathrm{~cm}$ e $9,0 \mathrm{~cm}$, com média de 6,0 $\mathrm{cm}$; do total de 1.691 indivíduos, apenas 18,4\% teve $7,0 \mathrm{~cm}$ ou mais de largura da carapaça (Botelho et al., 2009). Em Goiana (litoral norte de Pernambuco), variou entre $3,2 \mathrm{~cm} \mathrm{e} \mathrm{7,4} \mathrm{cm,}$ com média de $5,5 \mathrm{~cm}$; do total de 1.440 indivíduos, apenas $1,2 \%$ teve $7,0 \mathrm{~cm}$ ou mais de largura da carapaça (Santos \& Ribeiro, no prelo). Em Barra de Camaragibe (litoral norte de Alagoas), variou entre $1,7 \mathrm{~cm}$ e 7,0 cm, com média de $4,5 \mathrm{~cm}$; do total de 1.860 indivíduos analisados, apenas $0,3 \%$ teve $7,0 \mathrm{~cm}$ ou mais de largura da carapaça (Santos et al., no prelo) (Tabela 1).

Em Salvador (Bahia) as larguras varia- 
Tabela 1. Tamanho populacional do Cardisoma guanhumi em uma localidade do nordeste sub-oriental brasileiro (Rio Caravelas / Botelho et al., 2009) e três localidades do nordeste oriental brasileiro (Rio Camaragibe / Santos et al., no prelo; Rio Una / Botelho et al., 2001 e, Rio Goiana / Santos \& Ribeiro, no prelo).

\begin{tabular}{|c|c|c|c|c|}
\hline \multirow{2}{*}{$\begin{array}{c}\text { Largura da } \\
\text { Carapaça } \\
(\mathbf{m m})\end{array}$} & \multicolumn{4}{|c|}{ Locais } \\
\hline & $\begin{array}{c}\text { Rio Caravelas - } \\
\text { BA (2002-2003) }\end{array}$ & $\begin{array}{c}\text { Rio Camaragibe } \\
\text { - AL (2010) }\end{array}$ & $\begin{array}{l}\text { Rio Una - PE } \\
\text { (2000-2001) }\end{array}$ & $\begin{array}{c}\text { Rio Goiana - PB } \\
(2013)\end{array}$ \\
\hline \multicolumn{5}{|c|}{ MACHOS } \\
\hline Mínima & 30,0 & 20,0 & 34,0 & 35,0 \\
\hline Média & 60,0 & 45,0 & 52,0 & 55,0 \\
\hline Máxima & 90,0 & 70,0 & 72,0 & 74,0 \\
\hline Total & 699 & 968 & 717 & 742 \\
\hline \multicolumn{5}{|c|}{ FÊMEAS } \\
\hline Mínima & 32,0 & 17,0 & 31,0 & 32,0 \\
\hline Média & 61,0 & 45,0 & 50,0 & 54,0 \\
\hline Máxima & 81,0 & 67,0 & 74,0 & 72,0 \\
\hline $1^{\text {a }}$ Maturação & 47,0 & 40,0 & 43,0 & 43,0 \\
\hline Total & 992 & 892 & 723 & 698 \\
\hline $\begin{array}{l}\% \text { de } \mathrm{LC}=\text { de } 7 \mathrm{~cm} \\
\operatorname{acima}\left(\hat{\jmath}_{+}+{ }^{2}\right)\end{array}$ & 18,4 & 0,1 & 0,3 & 1,2 \\
\hline $\begin{array}{l}\% \text { de } \mathrm{LC}=\text { de } 6 \\
\mathrm{~cm} \text { acima }(\delta++)\end{array}$ & 71,2 & 1,7 & 5,2 & 21,4 \\
\hline
\end{tabular}

ram entre 3,5 cm e 7,0 cm (Carqueija, 2008); na Ilha de Itamaracá (Pernambuco) as larguras de 1.078 exemplares oscilaram de $2,1 \mathrm{~cm}$ a 7,0 $\mathrm{cm}$, com média de 4,3 cm (Costa \& Schwamborn, 2016); no Rio Grande do Norte, com um total de 3.670 indivíduos, distribuídos em duas áreas: de baixa pressão de captura (Natal), a média foi de $5,7 \mathrm{~cm}$ de largura da carapaça, enquanto o habitat com grande pressão de captura (Extremoz), a média registrada foi de 4,6 cm de largura da carapaça (Silva, 2013).

Com a ocorrência da sobrepesca ou a intensa destruição do habitat de guaiamum, é possível que, para garantir a manutenção de sua população, haja maturação precoce, que acarreta em um déficit no crescimento somáti- co, uma vez que iniciando o processo reprodutivo, a energia para o crescimento dos tecidos corpóreos é alocada para o crescimento das gônadas (Alunno-Bruscia \& Sainte Marie 1998; Hartnoll, 1985, 2006). Assim, estes indivíduos tendem a jamais chegarem ao tamanho comercial (Zheng, 2008).

No geral, o tamanho médio e, respectiva idade de primeira maturação gonadal do guaiamum pode variar de acordo com a longa distribuição geográfica da população, mas também por mudança provocada pelo esforço de pesca sobre um extrato da população.

Diversos valores foram registrados para a largura da carapaça na estimativa da primeira maturação gonadal do guaiamum, tais co- 
mo: 3,5 cm (Taissount, 1974), 4,2 cm (Botelho et al, 2001), 4,7 cm (Botelho et al 2009), 4,3 $\mathrm{cm}$ (Santos \& Ribeiro, no prelo), 4,0 cm (Santos et al., no prelo), 5,2 cm (Silva \& Oshiro, 2002), entre 3,5 e 4,0 cm ( Henning, 1975a,b), 4,8 cm (Leite, 2005), 5,5 cm (Rangel, 2005) e, em torno de 5,o cm em São Paulo (Gil, 2009). A partir dessas larguras de carapaça, metade da população $\left(\mathrm{L}_{50}\right)$ fica apta a reproduzir, portanto, garantindo a manutenção da população. Tal variação deve ser considerada pelos gestores do recurso, no sentido de regionalizar o tamanho mínimo de captura.

As larguras supracitadas são alcançadas quando os indivíduos possuem as seguintes idades: mais de 1,o ano (Taissount, 1974), 3,75 anos (Henning, 1975a, b), próximo a 1,0 ano (Botelho et al., 2001), 4,o anos (Silva \& Oshiro, 2002) e de 1,7 ano (Rangel, 2005).

É visível, ao longo do litoral brasileiro, a existência de alguns fatores que podem contribuir com uma considerável amplitude de largura da carapaça do guaiamum $(1,7 \mathrm{~cm}$ a $9,0 \mathrm{~cm})$. Além de fatores ambientais, essa variação pode estar atrelada às pressões seletivas impostas às populações de cada área de pesca. Assim, o seu tamanho médio corporal tende a ser maior em ambiente com baixa pressão de captura (Botelho et al., 2001; Silva, 2013). Entretanto, estudos com populações de C. guanhumi em três áreas protegidas e três áreas não protegidas em Porto Rico sugerem alguns resultados contraditórios, como: caranguejos com largura de carapaça maior em áreas não protegidas (Rodriguez-Fourquet \& Sabat 2009). Outros fatores podem contribuir com a amplitude de tamanho, tais como: a distribuição da população numa longa área geográfica, com diversas particularidades (Burggren et al., 1988) e, os diferentes fatores biológicos e ecológicos numa região geográfica, podem contribuir na variabilidade genética e afetar os padrões de estrutura da população de alguma espécie (Bilton et al., 2002). Assim, o guaiamum possui um forte apelo de investigação científica, já que estudos genéticos devem ser incentivados por serem escassos (Oliveira-Neto et al., 2008).

Numa investigação realizada sobre a variação genética e a conectividade de guaiamum em cinco estuários do estado de Pernambuco: no litoral norte (rio Goiana e rio Jaguaribe), central (rio Capibaribe) e no litoral sul (rio Sirinhaém e rio Formoso), foi constatado que o status de resiliente de C. guanhumi atesta para um bom estado de conservação da espécie no litoral de Pernambuco. Que ocorre uma alta diferenciação genética, sugerindo isolamento populacional por distância geográfica, nesse sentido, as populações de C. guanhumi do litoral Norte-Central (Goiana, Jaguaribe e Capibaribe) e Sul (Sirinhaém e Rio Formoso) comportam-se como diferentes unidades de manejo e devem ser gerenciadas de forma independente, por se comportar como diferentes Unidades Evolutivamente (Maia, 2014). O resultado dessa pesquisa é de extrema importância para o manejo da espécie, já que nos 187,0 km do litoral pernambucano foi constatada uma alta diferenciação genética e a existência de populações diferentes de guaiamuns. Pelo exposto, é recomendável que estudos genéticos sejam realizados ao longo do litoral brasileiro, onde a espécie se distribui por cerca de $6.780 \mathrm{~km}$ (menos no Rio Grande do Sul), para subsidiar um adequado uso da espécie.

Desta forma, para C. guanhumi há necessidade de constante monitoramento da estrutura populacional, principalmente da largura média anual da carapaça (por sexo). A preservação de seus habitats, se faz necessário para que a pesca desse crustáceo seja viabilizada econômica e ambientalmente. Com a atual largura mínima imposta em 7,0 cm de carapaça, haverá o esvaziamento dos apicuns pelas populações tradicionais que ficarão proibidas de o capturarem, portanto, contribuirá em potencializar a alteração desse habitat por grandes empreendimentos.

\section{Conclusão}

O cumprimento da Portaria Interministerial $\mathrm{n}^{0} 38$, de 26 de julho de 2018 , no seu art. $3^{\circ}$ I, que estabelece tamanho mínimo de captura do guaiamum em 7,0 cm de largura da carapaça em todo o território nacional, tornará a pesca do guaiamum inviável, principalmente 
no nordeste oriental brasileiro, gerando um grave conflito socioeconômico. Por outro lado, a destruição do habitat do guaiamum vai continuar sem controle, reduzindo a chance de recuperação da espécie.

Sugerimos que para essa sub-região do nordeste oriental, o tamanho mínimo de captura do guaiamum seja de $5,5 \mathrm{~cm}$ de largura da carapaça, possibilitando o uso do crustáceo como estratégia para conservação do seu habitat, o apicum, principalmente, por manter as populações tradicionais em seus territórios e, desta forma, garantir a diminuição da destruição do habitat, por grandes empreendimentos.

Outra questão preocupante, inserida no Art $6^{\circ} \mathrm{e}$ Art $7^{\circ}$ da Portaria Interministerial $n^{\circ}$ 38 / 2018 (Brasil, 2018b), é que a imensa maioria da captura de guaiamum ocorre fora das unidades de conservação de uso sustentável ou de áreas manejadas vinculadas aos planos de gestão. Não existindo instrumentos legais que definam a elaboração de áreas especialmente manejadas para o guaiamum. Portanto, com escassos recursos financeiros e humanos, os órgãos da administração pública federal e estadual dificilmente conseguirão implementar o uso sustentável do guaiamum fora de unidades de conservação. No que se refere a essa questão, há que se verificar a possibilidade do uso da Instrução Normativa no ${ }^{\circ}$. 29, de 31 de dezembro de 2002 (Brasil, 2002), referente a Acordos de Pesca, como instrumento de elaboração de Área Especialmente Manejada para Recuperação do Guaiamum.

Para os autores, essas alterações no marco legal do uso do guaiamum, consistem em caminhos para combater a ineficiência da gestão do uso desse recurso e, assim, promover a recuperação da sua população e garantir a conservação de seu ambiente.

\section{Referências Bibliográficas}

ALUNNO-BRUSCIA, M. \& SAINTE-MARIE, B. 1998. Abdomen allometry, ovary development, and growth of female snow crab, Chionoecetes opilio (Brachyura, Majidae), in the northwestern Gulf of St Lawrence. Canadian
Journal of Fisheries and Aquatic Sciences, 55: 459-477.

BILTON D. T., PAULA J. \& BISHOP J. D. D. 2002. Dispersal, genetic differentiation and speciation in estuarine organisms. Estuarine, Coastal and Shelf Science, 55(6): 937- 952.

BOTELHO, E. R. O., SANTOS, M. C. F. \& SOUZA, J. B. 2001. Aspectos populacionais do guaiamum, Cardisoma guanhumi Latreille, 1825, do estuário do rio Una (Pernambuco -Brasil). Boletim Técnico Científico do CEPENE, 9(1): 123-146.

BOTELHO, E. R. O; SANTOS, M. C. F; ALMEIDA, L; SILVA, C. G. M. 2009. Caracterização biológica do guaiamum, Cardisoma guanhumi, Latreille, 1825 (Decapoda: Gecarcinidae) do estuário do rio Caravelas (Caravelas - Bahia). Boletim Técnico-Científico do CEPENE, 17(1): 65-75.

BRASIL, 2006. Instrução Normativa MMA no 90/2006. Regulamenta a exploração do caranguejo guaiamum, goiamú, caranguejoazul, caranguejo-do-mato (Cardisoma guanhumi) nos estados do Ceará, Rio Grande do Norte, Paraíba, Pernambuco, Alagoas, Sergipe e Bahia, proibindo a captura de fêmeas bem como a retirada de partes isoladas (quelas, pinças ou garras), definindo o tamanho mínimo de captura e repassando aos superintendente estaduais a responsabilidade de estabelecer o defeso durante os períodos de andada. Diário Oficial [da] União, Brasília, DF, 03 de fev. de 2006.

BRASIL, 2007. Decreto no 6.040/2007. Institui a Política Nacional de Desenvolvimento Sustentável dos Povos e Comunidades Tradicionais. Diário Oficial [da] União, Brasília, DF, o8 de fev. de 2007.

BRASIL, 2014a. Portaria MMA no 43/2014. Institui o Programa Nacional de Conservação das Espécies Ameaçadas de Extinção - Pró-Espécies, com o objetivo de adotar ações de prevenção, conservação, manejo e gestão, com vistas a minimizar as ameaças e o risco de extinção de espécies. Diário Oficial [da] União, Brasília, DF, 05 de fev. de 2014.

BRASIL, 2014b. Portaria MMA no 445/2014. Reconhece como espécies de peixes e invertebrados aquáticos da fauna brasileira ameaçadas de 
extinção aquelas constantes da "Lista Nacional Oficial de Espécies da Fauna Ameaçadas de Extinção - Peixes e Invertebrados Aquáticos" . Diário Oficial [da] União, Brasília, DF, 18 de dez. de 2014.

BRASIL, 2015a. Portaria MMA no 98/2015. Altera a Portaria $\mathrm{n}^{0} 445 / 2014$, que reconhece espécies de peixes e invertebrados aquáticos da fauna brasileira ameaçadas de extinção aquelas constantes da "Lista Nacional Oficial de Espécies da Fauna Ameaçadas de Extinção - Peixes e Invertebrados Aquáticos. Diário Oficial [da] União, Brasília, DF, 29 de abr. de 2015.

BRASIL, 2015b. Portaria MMA no 163/2015. Altera art. da Portaria ${ }^{\circ} 445 / 2014$, que passa vigorar com a seguinte redação: $\S 4^{0}$ Para as espécies ameaçadas classificadas na categoria Criticamente em Perigo (CR) e Em Perigo (EN) de interesse econômico listadas no anexo III desta Portaria, o prazo previsto no caput será de 360 dias. Diário Oficial [da] União, Brasília, DF, o9 de jun. de 2015.

BRASIL, 2018a. Portaria MMA no 128/2018. Reconhece como passível de exploração, estudo ou pesquisa a espécie Cardisoma guainhumi (guaiamum, goiamú, caranguejo-azul, caranguejo-do-mato) e estabelece as respectivas condições. Diário Oficial [da] União, Brasília, DF, 30 de abr. de 2018.

BRASIL, 2018b. Portaria Interministerial SEAP/PR e MMA no 38/2018. Define regras para o uso sustentável e para a recuperação dos estoques da espécie Cardisoma guanhumi (guaiamum, goiamú, caranguejo-azul, caranguejo-do-mato). Diário Oficial [da] União, Brasília, DF, 27 de jul. de 2018.

BURGGREN, W. W., McMAHON, B. \& DOYLE, M. 1988. Biology of the land crabs. Cambridge, Univ. Press: 446p.

CARQUEIJA, C. R. G. (Coord.). 2008. Bioecologia do Cardisoma guanhumi Latreille (Crustacea, Decapoda, Gecarcinidae) no Rio Passa-Vaca, Salvador, Bahia. Relatório Técnico-Científico Final. Salvador: Faculdade de Tecnologia e Ciências.

COELHO-JR., C. 2010. Gradiente de inundação pelas marés e a drenagem terrestre sobre o comportamento da salinidade intersticial de bosque de mangue de Cananeia, São Paulo, Brasil. Revista da Gestão Costeira Integrada, Itajaí, v. 8. Disponível em: <www.aprh.pt/ rgci/pdf/rgcimang8o_Junior.pdf $>$. Acesso em: 2 mar. 2012.

COSTA, D. F. de M. \& SCHWAMBORN, R. 2016. Biologia populacional e ecologia trófica de Cardisoma guanhumi Latreille, 1825 em um manguezal de acesso restrito em Itamaracá, Pernambuco, Brasil. Tropical Oceanography, Recife, 44(2): 89-105.

HARTNOLL, R. G. 1985. Growth, sexual maturity and reproductive output. In: Wenner A.M. (ed.) Factors in adult growth. Rotterdam: A. A. Balkema, p. 15-17.

HARTNOLL, R. G. 2006. Reproductive investment in Brachyura. Hydrobiologia, 557: 3140.

HENNING, H. G. 1975a. Agressive, reproductive and molting behavior - Growth and maturation of Cardisoma guanhumi Latreille (Crustacea, Brachyura). Forma et Functio, 8 (1): $463-510$.

HENNING, H. G. 1975b. Oekologische, ethologische und sinnesphysiologische untersuchungen an der landkrabbe Cardisoma guanhumi Latreille (Decapoda, Brachyura). Forma et Functio, 8(1): $253-304$.

IBAMA - Instituto Brasileiro do Meio Ambiente e dos Recursos Naturais Renováveis. 2000. Centro de Pesquisa e Gestão de Recursos Pesqueiros do Litoral Nordeste. Boletim estatístico da pesca marítima e estuarina do Nordeste do Brasil - 1999. Tamandaré, PE, 157 p.

IBAMA - Instituto Brasileiro do Meio Ambiente e dos Recursos Naturais Renováveis. 2001. Centro de Pesquisa e Gestão de Recursos Pesqueiros do Litoral Nordeste. Boletim estatístico da pesca marítima e estuarina do Nordeste do Brasil - 2000. Tamandaré, PE, 139 p.

IBAMA - Instituto Brasileiro do Meio Ambiente e dos Recursos Naturais Renováveis. 2002. Centro de Pesquisa e Gestão de Recursos Pesqueiros do Litoral Nordeste. Boletim estatístico da pesca marítima e estuarina do Nordeste do Brasil - 2001. Tamandaré, PE, 140 p.

IBAMA - Instituto Brasileiro do Meio Ambiente e dos Recursos Naturais Renováveis. 2003. 
Centro de Pesquisa e Gestão de Recursos Pesqueiros do Litoral Nordeste. Boletim estatístico da pesca marítima e estuarina do Nordeste do Brasil - 2002. Tamandaré, PE, 209 p.

IBAMA - Instituto Brasileiro do Meio Ambiente e dos Recursos Naturais Renováveis. 2004. Centro de Pesquisa e Gestão de Recursos Pesqueiros do Litoral Nordeste. Boletim estatístico da pesca marítima e estuarina do Nordeste do Brasil - 2003. Tamandaré, PE, 191 p.

IBAMA - Instituto Brasileiro do Meio Ambiente e dos Recursos Naturais Renováveis. 2005a. Centro de Pesquisa e Gestão de Recursos Pesqueiros do Litoral Nordeste. Boletim estatístico da pesca marítima e estuarina do Nordeste do Brasil - 2004. Tamandaré, PE, 152 p.

IBAMA - Instituto Brasileiro do Meio Ambiente e dos Recursos Naturais Renováveis. 2005b. Centro de Pesquisa e Gestão de Recursos Pesqueiros do Litoral Nordeste. Relatório da primeira reunião sobre o ordenamento da cata do guaiamum Cardisoma guanhumi Latreille, 1825, na região nordeste do Brasil. Tamandaré, PE, 26 p.

IBAMA - Instituto Brasileiro do Meio Ambiente e dos Recursos Naturais Renováveis. 2011. Proposta de Plano Nacional de Gestão para o uso sustentável do caranguejo-uçá, do guaiamum e do siri-azul. Brasília, 156p.

ICMBIO - Instituto Chico Mendes de Conservação da Biodiversidade. 2018. Livro Vermelho da Fauna Brasileira Ameaçada de Extinção: Volume I / -- 1. ed. Brasília, DF: ICMBio/ MMA. $492 \mathrm{p}$.

LEITE, L. M. A. B. 2005. Estudo Etnocarcinológico dos catadores de Cardisoma guanhumi Latreille, 1825 (CRUSTACEA, BRACHYURA, GECARCINIDAE) no estuário do Rio Goiana, Pernambuco, Brasil. João Pessoa. 2005. 120 p. (Tese de Doutorado. Centro de Ciências Biológicas, UFPB).

MAIA, D. de J. G. 2014 Variação genética e a conservação do guaiamum (Cardisoma guanhumi, Decapoda: Gecarcinidae) em estuários do litoral de Pernambuco. Recife. 2014. 62 p. (Dissertação de Mestrado. Centro de Ciências Biológicas, UFPE). * A posição dessa referência deve ser alterada no artigo, pois está entre as letras $\mathrm{F} \mathrm{e} \mathrm{H}$.
MELO, G. A. S. 1996. Manual de identificação dos Brachyura (caranguejos e siris) do litoral brasileiro. Editora Plêiade, São Paulo, 6o3p.

MPA - MINISTÉRIO DA PESCA E AQUICULTURA. 2012. Boletim estatístico da pesca e aquicultura - 2011. Brasília, 60 p.

OLIVEIRA-NETO, J. F., PIE, M. R., CHAMMAS, M. A., OSTRENSKY, A. \& BOERGER, W. A. 2008. Phylogeography of the blue land crab, Cardisoma guanhumi (Decapoda : Gecarnicidae) along the Brazilian coast. J Mar Biol Assoc UK, 88: 1417-1423.

PINHEIRO, M. A. A.; SANTANA, W.; RODRIGUES, E. S.; IVO, C. T. C.; SANTOS, L. C. M.; TORRES, R.A.; BOOS, H.; DIAS-NETO, J. 2016. Avaliação dos Caranguejos Gecarcinídeos (Decapoda: Gecarcinidae). Cap. 13: p. 167-181. In PINHEIRO, M.; BOOS, H. (Org.). Livro Vermelho dos Crustáceos do Brasil: Avaliação 2010-2014, Porto Alegre, Sociedade Brasileira de Carcinologia, 466 p.

RANGEL, E. 2005. Parâmetros de Crescimento do Guaiamum, Cardisoma guanhumi, Latreille, 1825 (Crustacea : Decapoda : Gecarcinidae) no Nordeste do Brasil. Relatório da primeira reunião sobre o ordenamento da cata do guaiamum Cardisoma guanhumi Latreille, 1825, na região nordeste do Brasil. Tamandaré, PE, 26 p.

RODRÍGUEZ-FOURQUET, C. \& SABAT, A. M. 2009. Effect of harvesting, vegetation structure and composition on the abundance and demography of the land crab Cardisoma guanhumi in Puerto Rico. Wetlands Ecology and Management, 17(6): 627-640.

SANTOS, M. C. F.; BOTELHO, E. R. O; RIBEIRO, F. P.; IVO, C. T. C. Dinâmica populacional e reprodutiva de Cardisoma guanhumi (Brachyura : Gecarcinidae) em área de manguezal do rio Camaragibe (Alagoas - Brasil). No prelo.

SANTOS, M. C. F. \& RIBEIRO, F. P. Parâmetros populacionais do guaiamum Cardisoma guanhumi (Brachyura : Gecarcinidae) em área de manguezal da Reserva Extrativista AcauGoiana (Paraíba e Pernambuco - Brasil). No prelo. 
SCHMIDT, A. J.; BEMVENUTI, C. E.; DIELE, K. 2013. Sobre a definição da zona de apicum e sua importância ecológica para populações de caranguejo-uçá Ucides cordatus (LINNAEUS, 1763). Bol. Téc. Cient. CEPENE, Tamandaré PE, 19(1): 9-25.

SILVA, C. C. da. 2013. Cardisoma guanhumi Latreille, 1828 (Crustacea : Decapoda: Gecarcinidae) em duas áreas de manguezal no estado do Rio Grande do Norte com diferentes pressões de captura. Recife. 2013. 144 p. (Tese de Doutorado. Centro de Biologia Animal, UFPE).

SILVA, R. \& OSHIRO, L. M.Y. 2002. Aspectos da reprodução do caranguejo guaiamum Cardisoma guanhumi (Latreille) (Crustacea, Decapoda, Gecarcinidae) da Baía de Sepetiba, Rio de Janeiro, Brasil. Revista Brasileira de Zoologia, 19(1): 71-78.

TAISSOUNT, N. E. 1974. El Cangrejo de tierra Cardisoma guanhumi (Latreille) en Venezuela. Universidad dei Zulia. Maracaibo, Centro Investigationes Biológicas, $41 \mathrm{p}$.

WEDES, S. 2004. "Cardisoma guanhumi» (Online), Animal Diversity Web. Disponível em: $<$ http://animaldiversity.ummz.umich.edu/ site/accounts/information/ Cardisoma_guanhumi.html $>$. Acesso em: 02 ago. 2018.

ZHENG, J. 2008. Temporal Changes in Size at Maturity and Their Implications for Fisheries Management for Eastern Bering Sea Tanner Crab. Journal of Northwest Atlantic Fishery Science, 41: 137-149. 